\title{
Updated mtCOI reference dataset for the Bemisia tabaci
}

\section{species complex [version 1; peer review: 2 approved]}

\author{
Laura M. Boykin (D1), Anders Savill1, Paul De Barro² \\ ${ }^{1}$ School of Molecular Sciences and Australian Research Council Centre of Excellence in Plant Energy Biology, University of Western \\ Australia, Crawley, Perth, WA, Australia \\ ${ }^{2}$ CSIRO, Ecosciences Precinct, Brisbane, QLD, Australia
}

V1 First published: 13 Oct 2017, 6:1835

https://doi.org/10.12688/f1000research.12858.1

Latest published: 13 Oct $2017,6: 1835$

https://doi.org/10.12688/f1000research.12858.1

\section{Abstract}

Members of the whitefly Bemisia tabaci species complex cause millions of dollars of damage globally and are considered one of the world's most invasive species. They are capable of causing extensive damage to major vegetable, grain legume and fiber crops. All member of the species complex are morphologically identical therefore, data from the partial mitochondrial cytochrome oxidase subunit I (mtCOI) gene sequence has been used to identify the various species. The current reference dataset that is widely used is found on the CSIRO data portal. However, the reference set stored on the CSIRO data does not include newly added sequences (2013-2017), therefore an updated reference dataset is needed. All mtCOI data for the Bemisia tabaci species complex were downloaded on 22 May 2017 from GenBank and after quality checking, a dataset of 1,071 unique sequences and 696 base pairs was generated

(https://doi.org/10.6084/m9.figshare.5437420.v1).

\section{Keywords}

species identification, whitefly, insect vector, mitochondrial cytochrome oxidase, DNA barcoding

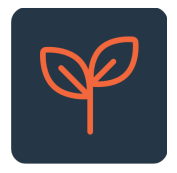

This article is included in the Agriculture, Food and Nutrition gateway.

\section{Open Peer Review \\ Approval Status 2 \\ version 1 \\ 13 Oct 2017

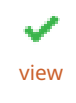

view \\ 1. Renate Krause Sakate ID, São Paulo State University (UNESP), Botucatu, Brazil \\ 2. Sharad Saurabh, CSIR-Central Institute of Medicinal and Aromatic Plants, Lucknow, India \\ Manisha Mishra (D), CSIR-Indian Institute of Toxicology Research, Lucknow, India \\ Any reports and responses or comments on the article can be found at the end of the article.}


Corresponding author: Laura M. Boykin (laura.boykin@uwa.edu.au)

Author roles: Boykin LM: Conceptualization, Data Curation, Formal Analysis, Investigation, Methodology, Project Administration, Resources, Software, Supervision, Validation, Visualization, Writing - Original Draft Preparation, Writing - Review \& Editing; Savill A: Conceptualization, Data Curation, Formal Analysis, Investigation, Methodology, Project Administration, Resources, Software, Supervision, Validation, Visualization, Writing - Original Draft Preparation, Writing - Review \& Editing; De Barro P: Conceptualization, Data Curation, Formal Analysis, Investigation, Methodology, Project Administration, Resources, Software, Supervision, Validation, Visualization, Writing - Original Draft Preparation, Writing - Review \& Editing

Competing interests: The authors have no competing interests.

Grant information: The author(s) declared that no grants were involved in supporting this work.

Copyright: $\odot 2017$ Boykin LM et al. This is an open access article distributed under the terms of the Creative Commons Attribution License, which permits unrestricted use, distribution, and reproduction in any medium, provided the original work is properly cited.

How to cite this article: Boykin LM, Savill A and De Barro P. Updated mtCOI reference dataset for the Bemisia tabaci species complex [version 1; peer review: 2 approved] F1000Research 2017, 6:1835 https://doi.org/10.12688/f1000research.12858.1

First published: 13 Oct 2017, 6:1835 https://doi.org/10.12688/f1000research.12858.1 


\section{Introduction}

Members of the Bemisia tabaci (whiteflies) species complex are among the world's most devastating insect pests and cause billions of dollars (US) of damage each year, leaving farmers in the developing world food insecure (De Barro et al., 2011). As a species complex with at least 34 members, identification is based on the use of the $657 \mathrm{bp}$ portion of the 3' end of the mitochondrial COI (mtCOI) (Boykin et al., 2012, Boykin et al., 2013). In order to identify members of the complex correctly, a curated reference dataset is a useful resource. In 2012, a reference mtCOI dataset was made available on the CSIRO data portal (De Barro \& Boykin, 2012). Errors in the dataset were subsequently identified and so the dataset was updated on 15 May 2017 (http://doi.org/10.4225/08/591a4018dfca8) (De Barro \& Boykin, 2017), but did not include new additions from GenBank (post 2012). Therefore, the dataset described herein represents the most up-to-date reference resource for members of the complex.

\section{Methods}

The CSIRO dataset (http://doi.org/10.4225/08/591a4018dfca8), updated 15 May 2017 was used as the starting point. The existing records were updated to include host plant data. New records post-2012 were then downloaded on 22 May 2017 directly from GenBank. All downloaded data was treated as follows:

1) Data was classified with BLAST using the new CSIRO reference data set
2) Sequences that caused gaps in the alignment were removed

2) Sequences that had stop codons present were removed

3) Clustal Omega (Sievers \& Higgins, 2014) was used for preliminary alignment and fine tuning of the alignment was carried out with MAFFT (Katoh \& Standley, 2013).

4) Duplicate sequences were then removed using BBMAP Dedupe (Bushnell, 2017).

In addition, all MEAM2 sequences were removed as they have now been confirmed to be pseudogenes (Tay et al., 2017).

\section{Data availability}

Figshare: Dataset 1. mtCOI reference data for species ID of Bemisia tabaci. DOI: 10.6084/m9.figshare.5437420 (Boykin et al., 2017)

\section{Competing interests}

The authors have no competing interests.

Grant information

The author(s) declared that no grants were involved in supporting this work.
Boykin LM, Armstrong KF, Kubatko L, et al.: Species delimitation and global biosecurity. Evol Bioinform Online. 2012; 8: 1-37. PubMed Abstract | Publisher Full Text | Free Full Text

Boykin LM, Bell CD, Evans G, et al.: Is agriculture driving the diversification of the Bemisia tabaci species complex (Hemiptera: Sternorrhyncha: Aleyrodidae)?: Dating, diversification and biogeographic evidence revealed. BMC Evol Biol. 2013; 13: 228.

PubMed Abstract | Publisher Full Text | Free Full Text

Boykin L, Savill A, De Barro P: mtCoI reference data for species ID of Bemisia tabaci. figshare. 2017

Data Source

Bushnell B: BBmap. 2017

Reference Source

De Barro P, Boykin LM: Global Bemisia dataset release version 31 Dec 2012. CSIRO. 2012.

Publisher Full Text
De Barro P, Boykin LM: Global Bemisia dataset release version 15 May 2017. CSIRO. 2017.

Publisher Full Text

De Barro PJ, Liu SS, Boykin LM, et al.: Bemisia tabaci: a statement of species status. Annu Rev Entomol. 2011; 56: 1-19.

PubMed Abstract | Publisher Full Text

Katoh K, Standley DM: MAFFT multiple sequence alignment software version 7: improvements in performance and usability. Mol Biol Evol. 2013; 30(4): 772-780. PubMed Abstract | Publisher Full Text | Free Full Text

Sievers F, Higgins DG: Clustal Omega, accurate alignment of very large numbers of sequences. Methods Mol Biol. 2014; 1079: 105-116.

PubMed Abstract | Publisher Full Text

Tay WT, Elfekih S, Court LN, et al:: The trouble with MEAM2: Implications of pseudogenes on species delimitation in the globally invasive Bemisia tabaci (Hemiptera: Aleyrodidae) cryptic species complex. Genome Biol Evol. 2017.

PubMed Abstract | Publisher Full Text 


\section{Open Peer Review}

\section{Current Peer Review Status:}

\section{Version 1}

Reviewer Report 08 November 2017

https://doi.org/10.5256/f1000research.13935.r26987

(C) 2017 Saurabh S et al. This is an open access peer review report distributed under the terms of the Creative Commons Attribution License, which permits unrestricted use, distribution, and reproduction in any medium, provided the original work is properly cited.

\section{Sharad Saurabh}

Molecular and Structural Biology Division, CSIR-Central Institute of Medicinal and Aromatic Plants, Lucknow, India

\section{Manisha Mishra}

Developmental Toxicology Division, CSIR-Indian Institute of Toxicology Research, Lucknow, India

Whitefly (Bemisia tabaci) is becoming a global hazard for crop and ornamental plants.

Identification of correct species is always better for the implication of best control strategy. In this regard, the effort made by Boykin et al for speedy and accurate identification of $B$. tabaci species complex is very significant. Additionally, the dataset developed with enriched quality is also very useful for whitefly biologist working in the area of evolution, mitochondrial genomics and crop management.

All the bioinformatics tools used to generate this refined dataset are ideal to make such analysis.

Is the rationale for creating the dataset(s) clearly described?

Yes

Are the protocols appropriate and is the work technically sound?

Yes

Are sufficient details of methods and materials provided to allow replication by others? Yes

Are the datasets clearly presented in a useable and accessible format?

Yes

Competing Interests: No competing interests were disclosed.

We confirm that we have read this submission and believe that we have an appropriate level of expertise to confirm that it is of an acceptable scientific standard. 
Reviewer Report 23 October 2017

https://doi.org/10.5256/f1000research.13935.r26988

(C) 2017 Sakate R. This is an open access peer review report distributed under the terms of the Creative Commons Attribution License, which permits unrestricted use, distribution, and reproduction in any medium, provided the original work is properly cited.

\section{Renate Krause Sakate}

Department of Plant Protection, Faculty of Agronomic Sciences, São Paulo State University (UNESP), Botucatu, Brazil

The updated mtCOI reference dataset for the Bemisia tabaci species complex will add a valuable contribution to researches for a fast and accurate identification of members from the $B$. tabaci species complex based on the partial mitochondrial COI gene.

The high quality data is easily accessible for download and gathers whiteflies collected globally. The availability of a reliable and updated reference dataset is an essential tool that will aid the scientific community to identify and classify correctly this pest, the first step in the crop management against whiteflies.

Is the rationale for creating the dataset(s) clearly described?

Yes

Are the protocols appropriate and is the work technically sound? Yes

Are sufficient details of methods and materials provided to allow replication by others? Yes

Are the datasets clearly presented in a useable and accessible format? Yes

Competing Interests: No competing interests were disclosed.

I confirm that I have read this submission and believe that I have an appropriate level of expertise to confirm that it is of an acceptable scientific standard. 
The benefits of publishing with F1000Research:

- Your article is published within days, with no editorial bias

- You can publish traditional articles, null/negative results, case reports, data notes and more

- The peer review process is transparent and collaborative

- Your article is indexed in PubMed after passing peer review

- Dedicated customer support at every stage

For pre-submission enquiries, contact research@f1000.com 